\title{
Species Diversity of Dickeya and Pectobacterium Causing Potato Blackleg Disease in Pakistan
}

\author{
Sohaib Sarfraz, ${ }^{1,2}$ Shahbaz Talib Sahi, ${ }^{2}$ Saïd Oulghazi, ${ }^{1,3}$ Kashif Riaz, ${ }^{2}$ Nasir Ahmed Rajput, ${ }^{2}$ Muhammad Atiq, \\ Muhammad Rizwan Tufail, ${ }^{2}$ Akhtar Hameed, ${ }^{2}$ and Denis Faure ${ }^{1, \dagger}$ \\ ${ }^{1}$ Université Paris-Saclay, CEA, CNRS, Institute for Integrative Biology of the Cell (I2BC), 91198, Gif-sur-Yvette, France \\ ${ }^{2}$ Department of Plant Pathology, Faculty of Agriculture, University of Agriculture Faisalabad 38000, Pakistan \\ ${ }^{3}$ Department of Biology, Faculty of Sciences, Moulay Ismail University, Meknes, Morocco
}

\begin{abstract}
Potato blackleg is caused by a diverse species of pectinolytic bacteria. In Pakistan, approximately $90 \%$ of the pathogens involved belong to Pectobacterium atrosepticum. Survey (2014 to 2017), sampling, and isolation from different potato growing areas of Punjab, Pakistan depicted an overall disease incidence of approximately $15 \%$. Thirtysix pectinolytic strains confirmed through biochemical and pathogenicity testing were characterized via gapA gene to identify them at the species level. To further validate the identification, one strain from each species SS26 (P. atrosepticum), SS28 (Pectobacterium polaris), SS70 (Dickeya dianthicola), SS90 (Pectobacterium parmentieri), SS95

$m t l D$, groEL, secY, glyA, gapA, and $r p l B)$. Phylogenetic analysis revealed considerable genetic diversity in the genus Pectobacterium. In silico DNA-DNA hybridization and average nucleotide identity values of the strains selected for genome sequencing were determined with other reference Pectobacterium and Dickeya strains. Moreover, all six representative strains were also phenotypically characterized on the basis of metabolism of different carbon sources. Overall, on the basis of genotypic and phenotypic characteristics, these 36 isolates were grouped into six species: $P$. atrosepticum, $P$. versatile, $P$. parmentieri, $P$. polaris, $P$. punjabense, and D. dianthicola.
\end{abstract} (Pectobacterium punjabense), and SS96 (Pectobacterium versatile) were selected for draft genome sequencing and multilocus sequence analysis of 13 housekeeping genes (fusA, rpoD, acnA, purA, gyrB, recA, mdh,
Keywords: Dickeya, diversity, genotypic, pathogen diversity, Pectobacterium pectinolytic, phenotypic, prokaryotes, vegetables
The causative agents of blackleg and soft rot diseases on potato plants and tubers belong to the Pectobacterium and Dickeya genera of the Pectobacteriaceae family (Adeolu et al. 2016). They are pectinolytic plant pathogens that represent a major threat to economically important crops of vegetables and ornamental plants (Czajkowski et al. 2011). Pectobacterium and Dickeya species have been included among the 10 most important bacterial plant pathogens based on their economic or scientific impact (Mansfield et al. 2012). Worldwide, they cause diseases on a broad spectrum of monocotyledonous and dicotyledonous plants such as potato, horseradish, yellow kiwifruit, tomato, cabbage, cucumber, artichoke, sunflower, bell pepper, cucurbit, and lettuce (Caruso et al. 2016). Pectobacterium and Dickeya species are responsible for causing potato blackleg in the field and tuber soft rot in the field and storage conditions, reducing the yield and quality of the tubers (Adeolu et al. 2016).

The Pectobacterium genus encompasses 18 species: $P$. atrosepticum, $P$. wasabiae, $P$. betavasculorum (Gardan et al. 2003), P. carotovorum (Kado 2010), P. cacticidum (Alcorn and Oldfield 1991; Hauben et al. 1999), $P$. parmentieri (Khayi et al. 2016), $P$. aroidearum (Nabhan et al. 2013), P. peruviense (Waleron et al. 2017), P. polaris (Dees et al. 2017), P. punjabense (Sarfraz et al. 2018), P. fontis (Oulghazi et al. 2019a), P. zantedeschia (Waleron et al. 2019a), $P$. aquaticum (Pédron et al. 2019), $P$. odoriferum, $P$. versatile, $P$. brasiliense, $P$. actinidiae (Portier et al. 2019), and P. polonicum

${ }^{\dagger}$ Corresponding author: D. Faure; denis.faure@i2bc.paris-saclay.fr

Funding: This work was supported by the Higher Education Commission's IRSIP program (Pakistan) through S.S., the CNRS (I2BC-SB2017), the Agence Nationale de la Recherche (ANR-15-CE21-0003) through D.F., and Grand Challenges Canada (Stars in Global Health, Round 7, grant no. 0664-01-10) through K.R.

The author(s) declare no conflict of interest.

Accepted for publication 26 November 2019

(C) 2020 The American Phytopathological Society
(Waleron et al. 2019b). Along with Pectobacterium, Dickeya species including Dickeya solani (van der Wolf et al. 2014), D. dadantii, D. $z e a e$, and D. dianthicola (Samson et al. 2005) were also found to be important plant pathogens (Potrykus et al. 2016). For several decades, $D$. dianthicola has been reported as a significant potato blackleg pathogen in the United States (Rosenzweig et al. 2016; Patel et al. 2019), Australia (Wright et al. 2018), and Europe (Toth et al. 2011).

The latest agricultural statistics (2017) show that potato is grown on 178,000 hectares with a total production of approximately 4.0 million tonnes. Pakistan ranks 6th and 19th in potato production in Asia and worldwide, respectively. The leading province in potato production is Punjab (95\%), followed by Khyber Pakhtunkhwa, Balochistan, and Sindh (FAOSTAT 2017). In Pakistan, blackleg of potato and soft rot of tubers were first reported in 1984 from Swat (Khan et al. 1985). A pluriannual survey of 42 locations including the plains and hilly areas of Pakistan revealed that the disease severity of blackleg of potato ranged from 2 to $30 \%$ and disease incidence from 5 to $35 \%$ (Ali et al. 2010). Blackleg and soft rot diseases affect potato production by reducing yield when blackleg incidence is $\leq 10 \%$ and by rotting the tubers during storage, affecting tuber export and seed certification (Farran and Mingo-Castel 2006). Until now no studies have monitored the genetic diversity of Pectobacterium and Dickeya potato pathogens in Pakistan. In this study, we analyzed and deposited in an international database a set of molecular information on the Pectobacterium and Dickeya potato pathogens in Pakistan that could be used for epidemiologic and diagnostic purposes.

\section{Materials and Methods}

Survey and sample collection. Seventy samples of Solanum tuberosum presenting blackleg symptoms were collected from major potato growing regions, namely Okara, Pakpattan, Depalpur, Chiniot, and Faisalabad of province Punjab, Pakistan. Bacteria were isolated from $1-\mathrm{cm}$ sections of symptomatic tissues suspended in $0.8 \%$ $\mathrm{NaCl}$ for $30 \mathrm{~min}$. Serial dilutions were plated onto crystal violet pectate (CVP) agar medium, and plates were incubated for $48 \mathrm{~h}$ at $28^{\circ} \mathrm{C}$ (Hélias et al. 2012). Bacterial colonies producing pitting on CVP were purified on nutrient agar (beef extract 3, peptone 5, glucose 2.5 , and agar $15 \mathrm{~g} /$ liter). All pectinolytic isolates were confirmed 
as gram-negative through Gram staining and $3 \% \mathrm{KOH}$ string test, and a $5 \% \mathrm{NaCl}$ salt tolerance test was also done to determine whether the isolated strains were sensitive to salt (Schaad et al. 2001). All isolates were preserved at $-80^{\circ} \mathrm{C}$ for storage in $25 \%$ glycerol.

gapA barcode analysis. Bacterial strains were subjected to PCR sequencing of the gapA barcode with the primers gapA-7-F (ATCAAAGTAGGTATCAACGG) and gapA-938-R (TCTACCA GAAACCAGTT). The gapA barcode was designed to identify Pectobacterium and Dickeya species (Cigna et al. 2017). Two microliters of a fresh liquid culture was diluted in $18 \mu$ l of Tris/EDTA buffer, followed by $10 \mathrm{~min}$ of heating at $99^{\circ} \mathrm{C}$ in a thermal cycler (Cigna et al. 2017). The reaction was completed at a final volume of $25 \mu \mathrm{l}$, including $1 \mu \mathrm{l}$ of DNA, $2.5 \mu$ l of PCR buffer $(10 \times)$, $2 \mu \mathrm{l}$ of $\mathrm{MgCl}_{2}(25 \mathrm{mM}), 2.5 \mu \mathrm{l}$ of $1 \mathrm{mM}$ of each dNTP, $1 \mu \mathrm{l}$ of each forward and reverse primer, and $0.1 \mu l$ of Taq polymerase. The amplification started by initial denaturation $\left(95^{\circ} \mathrm{C}\right.$ for $\left.5 \mathrm{~min}\right)$, followed by 30 cycles of denaturation $\left(95^{\circ} \mathrm{C}\right.$ for $\left.1 \mathrm{~min}\right)$, annealing $\left(56^{\circ} \mathrm{C}\right.$ for $\left.30 \mathrm{~s}\right)$, elongation $\left(72^{\circ} \mathrm{C}\right.$ for $\left.1 \mathrm{~min}\right)$, and a final extension step $\left(72^{\circ} \mathrm{C}\right.$ for $10 \mathrm{~min}$ ). At the end of amplification, PCR products were examined through gel electrophoresis with $2 \%$ agarose gel dipped in a solution containing $0.5 \mu \mathrm{g} / \mathrm{ml}$ of ethidium bromide for $30 \mathrm{~min}$ and visualized under the Gel doc system (Sambrook and Russell 2001). A standard 1-Kb DNA ladder was also run on each gel along with positive and negative controls. The obtained amplicons (932 bp) were sequenced via Sanger sequencing. Phylogenetic analyses were performed with Mega 7 software and the maximum likelihood method with 1,000 bootstrap replications.

Genome sequencing and analyses. One representative strain from each of the gapA-identified species ( $P$. atrosepticum SS26, $P$. polaris SS28, D. dianthicola SS70, $P$. parmentieri SS90, $P$. punjabense SS95, and $P$. versatile SS96) was selected for genome sequencing. DNA extraction was done with a DNA and RNA purification kit. The extraction was carried out with $5 \mathrm{ml}$ of the bacterial culture grown at $28^{\circ} \mathrm{C}$ overnight. Extracted DNA was mixed in $100 \mu \mathrm{l}$ of DNAse-free water, its quality was confirmed with a spectrophotometer, and it was preserved $-20^{\circ} \mathrm{C}$ for additional studies. The genome sequence was determined with a genomic DNA sequencer at the Institute for Integrative Biology of the Cell. Genomic data were assembled via de novo assembly in CLC Genomics Workbench version 10.1.1 (https://www.qiagenbioinformatics. com). Multilocus sequence analysis (MLSA), which is considered a general method to obtain an exact phylogenetic relationship of species within a genus, especially in prokaryotes, was used (Glaeser and Kämpfer 2015). CLC Genomics Workbench version 10.1.1 and MEGA 7 were used for MLSA and phylogenetic analyses, respectively. A robust MLSA of the concatenated gene fragments of the 13 housekeeping genes (fusA, rpoD, acnA, purA, gyrB, rec $A, m d h, m t l D$, groEL, sec $Y$, glyA, gapA, and $r p l B$ ) of Pakistani isolates was performed in comparison with the reference strains of Pectobacterium and Dickeya spp. available in the NCBI database to authenticate their identification at the species level (Oulghazi et al. 2019a, b). Moreover, the Genome-to-Genome Distance Calculator (http://ggdc.dsmz.de/) was used to calculate the in silico DNA-DNA hybridization (isDDH) values that approached the wet-lab DNA-DNA hybridization (DDH) as closely as possible (Meier-Kolthoff et al. 2013), and pairwise average nucleotide identity (ANI) values were obtained with the dedicated pipelines (http:// enve-omics.ce.gatech.edu/ani/) (Delcher et al. 2002). Therefore, we used genomic data for all six representative strains and the reference genomes from NCBI database to calculate the isDDH and ANI values by uploading the genomic DNA sequences on the respective web servers.

Pathogenicity test on potato tubers and plants. To confirm the pathogenicity of all six representative strains (SS26, SS28, SS70, SS90, SS95, and SS96), inoculations were done on potato tubers and plants (cultivar Sante) under controlled incubator and greenhouse conditions, respectively. Bacterial inoculum was prepared by inoculating a fresh, single bacterial colony in nutrient broth (NB) medium, and the bacterial culture was shaken at $200 \mathrm{rpm}$ at $28^{\circ} \mathrm{C}$ for 16 to $18 \mathrm{~h}$ in $10 \mathrm{ml}$ of NB media. The subsequent bacterial culture was centrifuged at 4,500 rpm for $10 \mathrm{~min}$. Bacterial pellet was washed twice with $0.8 \% \mathrm{NaCl}$ and resuspended in sterile $0.8 \% \mathrm{NaCl}$, adjusted to a final concentration of $10^{8} \mathrm{cfu} / \mathrm{ml}$ $\left(\mathrm{OD}_{600}=1\right)$ with a spectrophotometer (Hoque and Mansfield 2005).

Healthy potato tubers were washed, surface sterilized with $2 \%$ sodium hypochlorite for $10 \mathrm{~min}$, and rinsed with water, followed by air drying at room temperature. Ten microliters of bacterial cell suspension $\left(\mathrm{OD}_{600}=1\right)$ of each strain was inoculated with five replications, and boxes were placed in an incubator at $24^{\circ} \mathrm{C}$ for 4 days. For negative control, tubers were inoculated with $0.8 \% \mathrm{NaCl}$ solution.

Potato plants were grown in $20-\mathrm{cm}$ diameter pots at 24 to $26^{\circ} \mathrm{C}$ with regular watering in a greenhouse. Three weeks after stem emergence, potato plants were injected at $5 \mathrm{~cm}$ above the stem base with $100 \mu \mathrm{l}$ of bacterial cell suspension $\left(\mathrm{OD}_{600}=1\right)$ in a sterile syringe. The development of disease symptoms was observed daily for 2 weeks. Five plants were infected by each of the selected strains. Negative controls were injected with $0.8 \% \mathrm{NaCl}$ solution. For the tuber assay, we visually observed symptoms after 4 days of inoculation by cutting the tubers from the center, whereas in case of plants, inoculated stems were observed daily until clear blackleg symptoms appeared.

Phenotypic characterization. We phenotypically characterized all representative strains (SS26, SS28, SS70, SS90, SS95 ${ }^{\mathrm{T}}$, and SS96) by inoculating the minimal medium (M9) supplemented with different carbon sources including 1-0 $\beta$ methyl glucopyranoside, 1-0methyl- $\alpha$-D glucopyranoside, D-lactose, melibiose, gluconic acid, raffinose, galactose, cellobiose L-alanine, maltose, and D-mannose (Elbing and Brent 2002; Khayi et al. 2016). All six representative strains and the reference type strains including $P$. parmentieri RNS 08-42-1A ${ }^{\mathrm{T}}$, P. wasabiae CFBP $3304^{\mathrm{T}}$, D. dianthicola CFBP 2015 , and $D$. solani 0423.1 were used to determine and compare the phenotypic characters. All tests were carried out at $28^{\circ} \mathrm{C}$ for 24 to $48 \mathrm{~h}$ under $200 \mathrm{rpm}$ shaking (Terta et al. 2010).

\section{Results}

Isolation and identification of Pectobacterium and Dickeya pathogens. From 2014 to 2017, potato plants with blackleg symptoms were collected from five potato growing regions of Punjab, Pakistan. A total of 70 symptomatic plants were collected, from which 36 bacterial isolates showed pectinolytic activity on CVP medium (Table 1). All isolates were confirmed as gram-negative and sensitive to salt, because they did not grow in the presence of $5 \%$ $\mathrm{NaCl}$. The gapA barcode was amplified with gapA-7-F and gapA938-R primer and sequenced. BLAST searches of the NCBI database (http://www.ncbi.nlm.nih.gov) and phylogenetic analyses via maximum likelihood method (Mega7) (Fig. 1) revealed that 21 isolates belonged to $P$. atrosepticum, three isolates to $P$. versatile, three to $P$. parmentieri, three to $P$. punjabense, two to $P$. polaris, and four to $D$. dianthicola. GenBank accession numbers of the gapA sequences are listed in Table 1.

Genome sequencing and in silico analyses. Genome sequencing was done to confirm the phylogenetic position of the different strains at species level and to provide reference genomes from Pakistan. The characteristics of the genome sequences are presented in Table 2. Genomic data were collected from each of the six strains and reference strains of Pectobacterium and Dickeya spp. available in the NCBI database to perform MLSA by concatenating 13 housekeeping genes (fusA, rpoD, acnA, purA, gyrB, recA, mdh, mtlD, groEL, secY, glyA, gapA, and $r p l B$ ) (Fig. 2). All six Pakistani strains (SS26, SS28, SS70, SS90, SS95, and SS96) first identified with the gapA gene were clustered with the same clades or groups as respective species (Figs. 1 and 2). Hence, the gapA barecode unambiguously assigned the appropriate taxon (genus, species, and subspecies).

Furthermore, genomic data were also used to calculate isDDH and ANI values by using bioinformatics websites (mentioned in Materials and Methods). IsDDH and ANI values were calculated for all six Pakistani strains (SS26, SS28, SS70, SS90, SS95, and SS96) and other Pectobacterium and Dickeya strains as queries to assess whether such in silico methods can be used as substitutes of wet-lab 
DDH to conclude species allocation of these plant pathogenic strains. Therefore, the isDDH and ANI values were consistent with their phylogenetic relationships (Figs. 1 and 2) because strains grouped in the same phylogenetic clade also showed high isDDH and ANI values. The ANI and isDDH values calculated for different species of Pectobacterium and Dickeya were well below the suggested $96 \%$ cutoff for the ANI value and $70 \%$ cutoff for the isDDH value for delineating the species (Table 3).

Virulence on potato plant host. Results of the pathogenicity tests showed that all representative strains including SS26 (P. atrosepticum), SS28 ( $P$. polaris), SS90 ( $P$. parmentieri), SS95 ( $P$. punjabense), SS96 ( $P$. versatile), and $D$ dianthicola strain (SS70) produced typical blackleg symptoms on inoculated potato plants and induced maceration on potato tubers, with five replications for each of the six strains used. In case of potato plants, 2 weeks after inoculation, all inoculated stems showed black, rotten stems, including positive controls, but the negative control plants remained symptomless. Similarly, in the tuber assay, all infected tubers exhibited maceration 4 days after inoculation, but not those inoculated with $0.8 \% \mathrm{NaCl}$ solution.

Phenotypic analyses. All six representative strains were phenotypically characterized on the basis of ability to use different carbon sources as compared with the closest type or reference strains. In case of Pectobacterium strains, positive results were obtained with 1-0 $\beta$ methyl glucopyranoside, D-lactose, melibiose, gluconic acid, raffinose, galactose, cellobiose, and D-mannose, whereas negative results with 1-0methyl- $\alpha$-D glucopyranoside, L-alanine, and D-maltose. In case of D. dianthicola strains (SS70 and CFBP 2015), positive growth was obtained with L-rhamnose but no growth with D-arabinose. In contrast, reference strain $D$. solani 0423.1 showed opposite results for both of the aforementioned carbon sources, thus differentiating the D. dianthicola strains on the basis of phenotypic characters (Table 3).

\section{Discussion}

Blackleg and soft rot diseases of potato are among the most important bacterial diseases because they adversely affect the potato (S. tuberosum) trade worldwide (McNally et al. 2017). Recent advancements in the classification of blackleg-causing bacteria and occurrence of newly emerging pathogens such as Dickeya species have encouraged many scientists to characterize the overall diversity of blackleg-related pathogens (Jiang et al. 2016). The results of this study highlight the diversity of blackleg pathogens that threaten potato production and can be used to reduce the risk of economic losses caused by this disease through better quarantine measures. Therefore, from 2014 to 2017,70 potato plant samples exhibiting blackleg disease were collected from different farmers' fields in five potato growing regions of Punjab, Pakistan. These surveys found an overall disease incidence of approximately $15 \%$ in the country's most important potato producing regions.

A multiple approach of genomic pathogenicity tests and phenotypical (biochemical) characterization were done to explore the genetic diversity of pectinolytic bacteria isolated from typical blackleg symptoms of potato (Rosselló-Mora and Amann 2001). Homogeneity was almost constant in case of the phenotypic properties; in contrast, genomic analyses of the isolates showed the diversity among all

Table 1. Strains isolated and identified in this study

\begin{tabular}{|c|c|c|c|c|c|c|}
\hline $\begin{array}{l}\text { Strain } \\
\text { code }\end{array}$ & $\begin{array}{c}\text { Sample collection } \\
\text { date }\end{array}$ & Location & $\begin{array}{l}\text { Potato plant } \\
\text { tissue }\end{array}$ & $\begin{array}{c}\text { Pathogenicity on } \\
\text { tubers }^{\mathrm{a}}\end{array}$ & $\begin{array}{l}\text { Species assignation } \\
\text { based on gapA }\end{array}$ & $\begin{array}{c}\text { gapA accession number } \\
\text { (GenBank) }\end{array}$ \\
\hline SS12 & 07-01-2016 & Depalpur1 & Stem & 2 & Pectobacterium atrosepticum & MK392510 \\
\hline SS13 & 07-01-2016 & Depalpur1 & Stem & 2 & P. atrosepticum & MK392511 \\
\hline SS14 & 07-01-2016 & Depalpur2 & Stem & 1 & P. atrosepticum & MK392512 \\
\hline SS15 & $07-01-2016$ & Depalpur2 & Stem & 2 & P. atrosepticum & MK392513 \\
\hline SS16 & $07-01-2016$ & Depalpur3 & Stem & 2 & P. atrosepticum & MK392514 \\
\hline SS17 & $07-01-2016$ & Depalpur3 & Stem & 2 & P. atrosepticum & MK392515 \\
\hline SS18 & $30-12-2015$ & Pakpattan 1 & Stem & 2 & P. atrosepticum & MK392516 \\
\hline $\mathrm{SS} 22$ & $30-12-2015$ & Pakpattan2 & Stem & 1 & P. atrosepticum & MK392517 \\
\hline SS23 & $30-12-2015$ & Pakpattan2 & Stem & 1 & P. atrosepticum & MK392518 \\
\hline $\mathrm{SS} 24$ & $30-12-2015$ & Pakpattan2 & Stem & 2 & P. atrosepticum & MK392519 \\
\hline SS25 & $30-12-2015$ & Pakpattan2 & Stem & 1 & P. atrosepticum & MK392520 \\
\hline SS26 & $16-01-2016$ & Okara 1 & Stem & 1 & P. atrosepticum & MK392521 \\
\hline SS28 & 14-01-2017 & Okara 2 & Stem & 1 & Pectobacterium polaris & MH188893 \\
\hline SS32 & 24-12-2014 & Okara 2 & Stem & 2 & P. atrosepticum & MK392522 \\
\hline SS33 & 24-12-2014 & Okara 2 & Stem & 1 & P. atrosepticum & MK392523 \\
\hline SS54 & $16-01-2017$ & Chiniot 1 & Stem & 2 & Pectobacterium punjabense & MH603864 \\
\hline SS56 & $16-01-2017$ & Chiniot 1 & Stem & 1 & P. punjabense & MH603865 \\
\hline SS57 & $20-12-2015$ & Chiniot 2 & Stem & 1 & P. atrosepticum & MK392524 \\
\hline SS64 & $15-01-2014$ & Okara 3 & Stem & 2 & P. atrosepticum & MK392525 \\
\hline SS65 & $15-01-2014$ & Okara 3 & Stem & 2 & P. atrosepticum & MK392526 \\
\hline SS70 & 14-01-2017 & Okara 3 & Stem & 2 & Dickeya dianthicola & MG845896 \\
\hline SS71 & $20-12-2015$ & Chiniot 4 & Stem & 2 & P. atrosepticum & MK392527 \\
\hline SS72 & $20-12-2015$ & Chiniot 4 & Stem & 2 & P. atrosepticum & MK392528 \\
\hline SS82 & $15-01-2014$ & Okara 3 & Stem & 2 & P. atrosepticum & MK392529 \\
\hline SS84 & 14-01-2017 & Okara 4 & Stem & 2 & D. dianthicola & MG845897 \\
\hline SS85 & 14-01-2017 & Okara 4 & Stem & 1 & D. dianthicola & MG845898 \\
\hline SS86 & 14-01-2017 & Okara 4 & Stem & 1 & D. dianthicola & MG845899 \\
\hline SS90 & $20-12-2015$ & Chiniot 2 & Stem & 2 & Pectobacterium parmentieri & MH188895 \\
\hline SS91 & $20-12-2015$ & Chiniot 2 & Stem & 2 & P. parmentieri & MH188896 \\
\hline SS92 & $20-12-2015$ & Chiniot 2 & Stem & 2 & P. parmentieri & MH188897 \\
\hline SS93 & 14-01-2017 & Okara 3 & Stem & 2 & P. atrosepticum & MK392530 \\
\hline SS94 & 14-01-2017 & Okara 2 & Stem & 1 & $P$. polaris & MH188894 \\
\hline SS95 & $16-01-2017$ & Chiniot 1 & Stem & 2 & P. punjabense & MH603866 \\
\hline SS96 & 05-01-2016 & Faisalabad & Stem & 2 & Pectobacterium versatile & MK029455 \\
\hline SS97 & 05-01-2016 & Faisalabad & Stem & 2 & P. versatile & MK029456 \\
\hline SS98 & 05-01-2016 & Faisalabad & Stem & 1 & P. versatile & MK029457 \\
\hline
\end{tabular}

a Numbers indicate aggressiveness levels in tuber maceration assays (1, virulent; 2, more virulent). 
these pectinolytic strains (Gallelli et al. 2009; Yahiaoui-Zaidi et al. 2003). This study confirmed that the commonly described major potato pectinolytic pathogens including $P$. atrosepticum, $P$. versatile, $P$. parmentieri, $P$. polaris, $D$. dianthicola, and the recently identified $P$. punjabense species also exist in Pakistan (Sarfraz et al. 2018). These results are important because many Pectobacterium species have also been reported as the most important blackleg and soft rot pathogens in Morocco and
Turkey (Faquihi et al. 2015; Ozturk et al. 2018; Terta et al. 2010). Therefore, to identify the bacteria belonging to the Pectobacteriaceae family and especially to characterize the pectinolytic bacteria (Pectobacterium and Dickeya genera), a PCR-sequencing tool designed by Cigna et al. (2017) was used. Hence, the analysis with gapA sequences enabled us to identify all pectinolytic bacteria at species level in six different clades. Clade I includes strains of $P$.

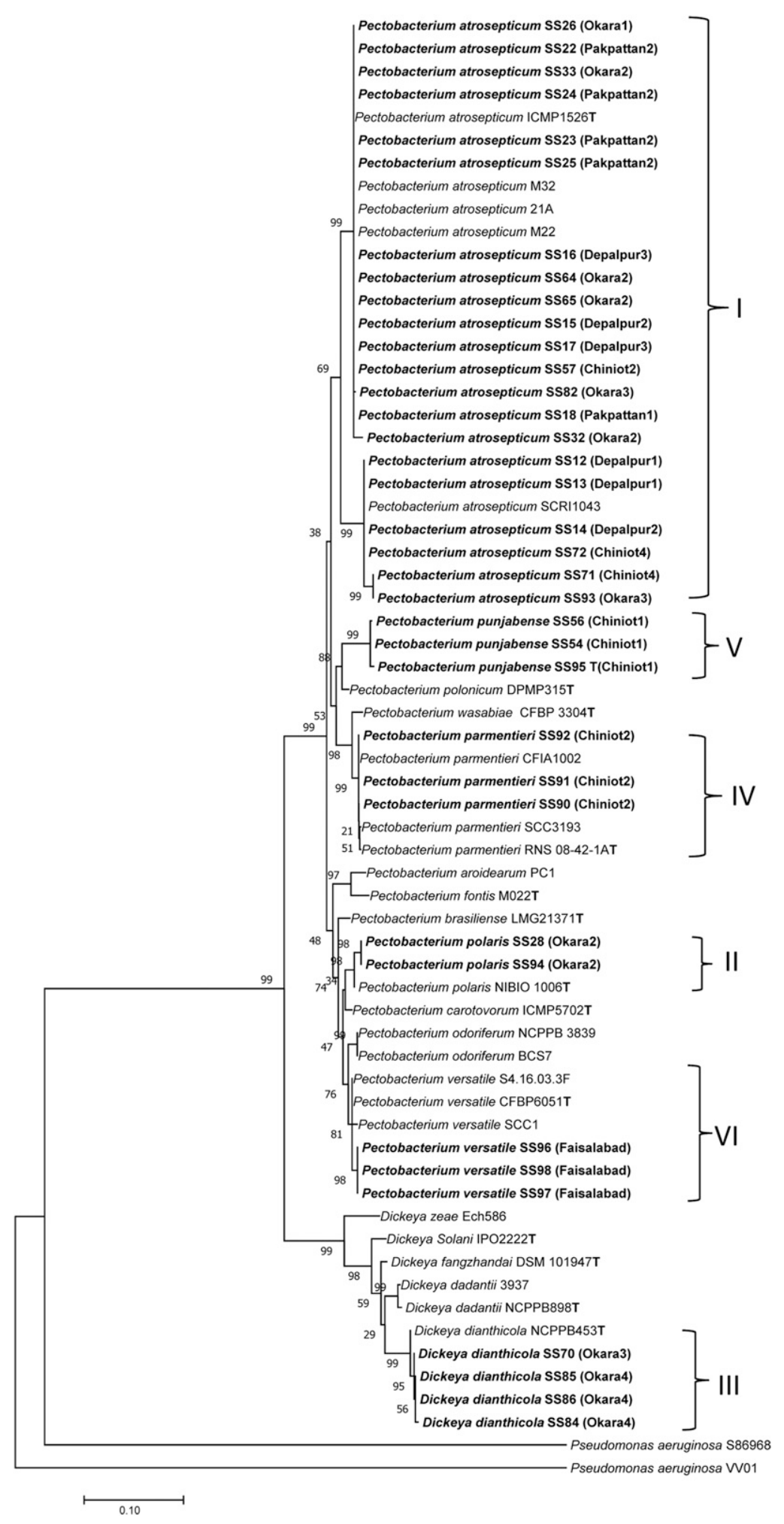

Fig. 1. Phylogenetic analysis of all species identified in this study based on their gapA nucleotide sequences. Strains in bold letters are from this study, whereas all others are reference strains from the NCBI database. Phylogenetic analyses were conducted in MEGA7 software by maximum likelihood method. Pseudomonas aeruginosa strains were used as an outgroup to root the phylogeny tree. 
atrosepticum, clustered with the reference strain $P$. atrosepticum 1526; clade II comprises strains of $P$. polaris clustered with the reference strain $P$. polaris NIBIO 1006; and clade III includes strains of $D$. dianthicola clustered with $D$. dianthicola GBBC2039. Similarly, clade IV includes strains of $P$. parmentieri clustered with its reference strain $P$. parmentieri RNS 08-42-1A, whereas clade V includes strains of $P$. punjabense clustered distinctly with its closest relatives, $P$. wasabiae CFBP 3304 and $P$. parmentieri RNS 08-42-1A. Meanwhile, clade VI consists of $P$. versatile strains, which also linked to its respective clade with $P$. versatile CFBP6051 (Figs. 1 and 2).

Overall, molecular characterization showed that $88 \%$ of isolates belonged to Pectobacterium and $12 \%$ to Dickeya species. Of the 36 isolates, Chiniot showed the presence of diverse species of Pectobacterium, including three strains of $P$. atrosepticum, three of $P$. parmentieri, and three of the newly identified $P$. punjabense. However, the representative isolates of the Okara region showed the presence of genus Pectobacterium and Dickeya, with two strains of $P$. polaris, eight strains of $P$. atrosepticum, and four strains of D. dianthicola. Moreover, the Faisalabad region showed $100 \%$ prevalence of $P$. versatile with three strains; similarly, the other two regions, Depalpur and Pakpattan, also showed 100\% occurrence, but of $P$. atrosepticum, with five strains from each region. Therefore, our study clearly validates the predominance of $P$. atrosepticum in Pakistan. By and large, high variability between the Pectobacterium species isolated from five different regions of the Punjab province has been observed. Similarly, Ozturk et al. (2018) and Faquihi et al. (2015) observed a good diversity among their isolates selected for molecular characterization, tested with multiplex PCR and with species-specific PCR, and identified different strains as $P$. atrosepticum, $P$. carotovorum subsp. brasiliense, $P$. carotovorum, and $P$. parmentieri.

Some recent studies have revealed changes in the positioning of a number of strains within Pectobacterium and Dickeya species and highlighted the need for species reclassification based on genomic data (Khayi et al. 2015; Nykyri et al. 2012; Pritchard et al. 2016; Zhang et al. 2016). Thus, on the basis of gapA sequence analyses, it was decided to genome sequence representative strains from each group to get more insight from genomic studies. Therefore, one strain from each of six species was selected for draft genome sequencing to confirm their taxonomic position in the tree via MLSA. Khayi et al. (2016) also reestablished the taxonomic position of $P$. wasabiae to $P$. parmentieri by using molecular methods such as MLSA (Glaeser and Kämpfer 2015) and genome-to-genome distance (Meier-Kolthoff et al. 2013). The new species-level clade, differentiated from the other group of Pectobacterium species based on the results of a phylogenetic tree constructed by concatenating seven housekeeping genes (acnA, gapA, icdA, $m d h, m t l D, p g i$, and $p r o A)$, has also been reported by Ma et al. (2007) and Nabhan et al. (2012). Moreover, Oulghazi et al. (2019a, b) used 13 housekeeping genes (fusA, rpoD, rpoS, glyA, purA, groEL, gapA, rplB, leuS, recA, gyrB, infB, and secY) in MLSA to confirm the existence of new Pectobacterium and Dickeya species. Therefore, based on the earlier studies, a robust phylogenetic analysis of the six representative strains and reference strains from NCBI database was done via MLSA of 13 housekeeping genes (fusA, rpoD, acnA, purA, gyrB, recA, $m d h$, $m t l D$, groEL, secY, glyA, gapA, and $r p l B$ ) that exist in nearly all Pectobacteriaceae belonging to the genera Pectobacterium and Dickeya
(Fig. 2). Therefore, all six representative strains were placed in six different groups or clades, showing the same results as with gapA sequence analysis (Fig. 2). In addition, at the genome scale, several in silico methods were also available to evaluate assignation to existing species and proposition of novel species. Khayi et al. (2016) used isDDH and ANI values to differentiate the pairings between $P$. wasabiae CFBP 3304T and two $P$. parmentieri strains (RNS 08-42-1AT and RNS14.18.2.1A), which showed 68.5 and $67.4 \%$ isDDH values, respectively, thus ensuring the transfer of the $P$. wasabiae to $P$. parmentieri. Similarly, Waleron et al. (2019a) identified and reported a new species, Pectobacterium zantedeschiae, by genome sequencing the strains and making their comparison with whole genome sequences of other Pectobacterium type strains by using isDDH and ANI values. Therefore, we also used genomic data from our six strains to calculate isDDH and ANI values. When phylogenetic relatives were compared, $\mathrm{ANI}$ and isDDH values were consistent with the existing identifications of the taxonomic position of these species, which had been generally depended on wet-lab DDH values, biochemical tests, and 16S rRNA sequencing (Brady et al. 2012; Gardan et al. 2003). However, the ANI and isDDH values found in this study were very much in line with the results of the phylogenetic studies of gapA sequences alone

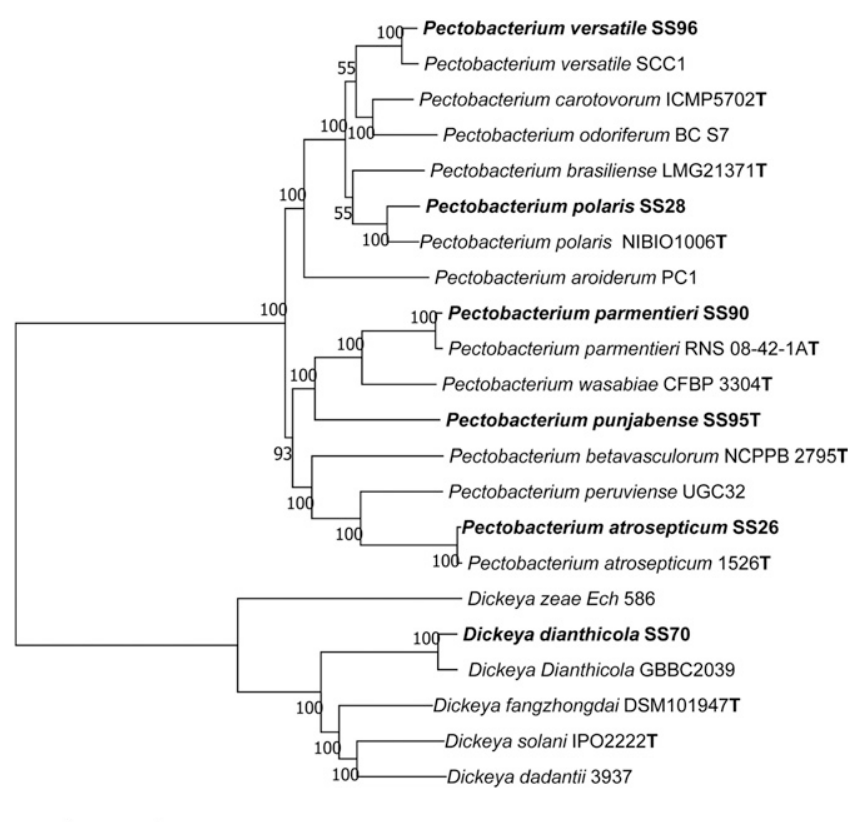
0.020

Fig. 2. Phylogenetic tree based on multilocus sequence analysis (MLSA). Six representative strains from each species (SS26, SS28, SS70, SS90, SS95, and SS96) were selected for MLSA based on concatenated genes fusA, rpoD, rpoS, acnA, purA, recA, $m d h, m t I D$, groEL, secY, glyA, gapA, and $r p l B$. The evolutionary history was inferred via the neighbor-joining method. The percentage of replicate trees in which the associated taxa clustered together in the bootstrap test $(1,000$ replicates) is shown next to the branches. The evolutionary distances were computed via maximum composite likelihood method and are in the units of the number of base substitutions per site. The analysis involved 22 nucleotide sequences. There were a total of 17,940 positions in the final dataset. Evolutionary analyses were conducted in MEGA7.

Table 2. Accession number and statistics for the draft genome sequences

\begin{tabular}{|c|c|c|c|c|c|c|c|}
\hline Strain & $\begin{array}{c}\text { GenBank } \\
\text { accession number }\end{array}$ & $\begin{array}{l}\text { Genome } \\
\text { size (bp) }\end{array}$ & $\begin{array}{c}\text { Contig } \\
\text { N50 (bp) }\end{array}$ & $\begin{array}{l}\text { No. of } \\
\text { contigs }\end{array}$ & $\begin{array}{l}\text { No. of coding } \\
\text { DNA sequences }\end{array}$ & $\begin{array}{l}\text { No. of transfer } \\
\text { RNAs }\end{array}$ & $\begin{array}{l}\text { Genome } \\
\text { coverage }\end{array}$ \\
\hline Pectobacterium atrosepticum SS26 & QESY00000000 & $4,927,512$ & 90,297 & 110 & 4,293 & 60 & 36 \\
\hline P. polaris $\mathrm{SS} 28$ & QESX00000000 & $4,722,413$ & 243,038 & 37 & 4,174 & 59 & 56 \\
\hline Dickeya dianthicola SS70 & QESZ00000000 & $4,797,592$ & 177,218 & 62 & 4,163 & 59 & 71 \\
\hline P. parmentieri SS90 & QESW00000000 & $4,917,173$ & 176,176 & 50 & 4,395 & 62 & 64 \\
\hline P. punjabense SS95 & PYSO00000000 & $4,732,531$ & 116,258 & 73 & 4,193 & 64 & 72 \\
\hline P. versatile SS96 & QESV00000000 & $5,042,015$ & 211,427 & 64 & 4,382 & 61 & 60 \\
\hline
\end{tabular}


and by MLSA of 13 housekeeping genes. All genomes used in these in silico analyses found ANI and isDDH values well below the suggested 96\% cutoff for the ANI value and $70 \%$ cutoff for the isDDH value when distinct species were compared (Table 3 ). Similarly, some previous studies reported that most intraspecies ANI values were $\geq 96 \%$ and isDDH values were $\geq 70 \%$ (Colston et al. 2014; Zhang and Qui 2015; Zhang et al. 2016).

Different Pectobacterium species can also be differentiated from all other strains solely on the basis of acid production from different carbon sources supplemented in minimal M9 medium (Elbing and Brent 2002). Positive results were obtained with 1-0 $\beta$ methyl glucopyranoside, D-lactose, melibiose, gluconic acid, raffinose, galactose, cellobiose, and D-mannose, whereas negative results were obtained with 1-0-methyl- $\alpha$-D glucopyranoside, L-alanine, and maltose (Table 3). These results were consistent with the results of Khayi et al. (2016), in which different Pectobacterium species were phenotypically distinguished from $P$. wasabiae strains by producing acids from (+)-raffinose, a-D(+)a-lactose, $\mathrm{D}(+)$-galactose, and (+)-melibiose but not from methyl a-D-glucopyranoside, (+)-maltose, or malonic acid. Moreover, recently proposed $P$. punjabense strain $\mathrm{SS}^{2} 5^{\mathrm{T}}$ showed completely different results, when tested along with its nearby aligning strain $P$. wasabiae CFBP 3304T, by producing acids from melibiose, raffinose, and galactose (Table 4) (Sarfraz et al. 2018; Khayi et al. 2016).

\section{Conclusion}

Our work revealed the diversity of pectinolytic pathogens of potato plants in Pakistan. These characteristics are important for effective epidemiological observations and avoidance and management of these important plant pathogens. Thus, given the diversity of blackleg pathogens in different regions of Pakistan including Okara, Chiniot, Faisalabad, Depalpur, and Pakpattan, a high risk of potato blackleg outbreaks can be assumed in the near future as the numbers of fields are increased because of the demand for potato production. Because these pectinolytic bacteria are multihost pathogens, their occurrence in potato fields may put other crops at risk, such as chili, tomato, pepper, and cucumber. The presented study is the first step in characterizing the population of Pectobacterium and Dickeya spp. to evaluate the danger of pectinolytic bacteria in different regions of Pakistan.

Table 3. Average nucleotide identity (ANI) and in silico DNA-DNA hybridization (isDDH) values ${ }^{\mathrm{a}}$

\begin{tabular}{|c|c|c|c|c|c|c|c|c|c|c|c|c|c|c|c|c|c|}
\hline & & \multicolumn{16}{|c|}{ ANI values } \\
\hline \multicolumn{2}{|c|}{ Strains } & 1 & 2 & 3 & 4 & 5 & 6 & 7 & 8 & 9 & 10 & 11 & 12 & 13 & 14 & 15 & 16 \\
\hline 1 & Pectobacterium atrosepticum SS26 & - & 99.5 & 88.8 & 88.9 & 88.8 & 88.8 & 89.1 & 89.1 & 88.7 & 89.3 & 92.8 & 88.7 & 91.1 & 79.2 & 79.2 & 79.3 \\
\hline 2 & P. atrosepticum ICMP1526T & 94.6 & - & 88.7 & 89.0 & 89.0 & 89.0 & 89.1 & 89.1 & 88.0 & 89.5 & 93.4 & 88.7 & 92.1 & 79.2 & 79.4 & 79.5 \\
\hline 3 & P. versatile SS96 & 38.5 & 38.2 & - & 95.1 & 93.5 & 93.4 & 88.0 & 88.0 & 88.0 & 88.2 & 87.9 & 92.2 & 88.0 & 79.6 & 79.4 & 79.4 \\
\hline 4 & $\begin{array}{l}\text { P. carotovorum subsp. carotovorum } \\
\text { ICMP5702T }\end{array}$ & 38.6 & 39.1 & 63.3 & - & 92.9 & 92.2 & 88.0 & 88.0 & 88.2 & 88.2 & 88.0 & 92.9 & 88.1 & 79.0 & 78.8 & 79.0 \\
\hline 5 & P. polaris SS28 & 38.2 & 38.2 & 54.1 & 52.2 & - & 96.8 & 88.1 & 88.0 & 88.1 & 88.1 & 88.1 & 93.7 & 88.1 & 79.2 & 79.0 & 79.4 \\
\hline 6 & P. polaris NIBIO $1006 \mathrm{~T}$ & 38.4 & 38.8 & 54.3 & 52.3 & 73.9 & - & 88.0 & 88.0 & 88.2 & 88.2 & 87.8 & 93.6 & 88.0 & 79.5 & 79.3 & 79.5 \\
\hline 7 & P. parmentieri SS90 & 39.2 & 39.3 & 36.5 & 36.3 & 36.4 & 36.4 & - & 99.0 & 90.7 & 93.6 & 88.1 & 88.2 & 87.8 & 79.2 & 79.0 & 79.4 \\
\hline 8 & P. parmentieri RNS 08-42-1AT & 39.2 & 39.3 & 36.3 & 36.5 & 36.4 & 36.4 & 91.0 & - & 90.7 & 93.6 & 88.2 & 88.3 & 87.7 & 79.1 & 79.0 & 79.7 \\
\hline 9 & P. punjabense SS95 & 38.4 & 38.0 & 36.4 & 36.8 & 36.7 & 36.9 & 44.1 & 44.1 & - & 90.4 & 87.8 & 88.7 & 87.6 & 79.2 & 79.1 & 78.9 \\
\hline 10 & P. wasabiae CFBP 3304T & 39.9 & 40.0 & 36.8 & 36.8 & 36.5 & 36.8 & 54.8 & 54.7 & 43.3 & - & 88.3 & 88.2 & 88.0 & 79.3 & 79.2 & 79.8 \\
\hline 11 & P. peruviense IFB5232T & 51.4 & 49.2 & 36.4 & 36.1 & 36.4 & 35.6 & 36.2 & 36.7 & 36.2 & 36.7 & - & 90.1 & 90.5 & 77.5 & 77.2 & 77.6 \\
\hline 12 & $\begin{array}{l}\text { P. carotovorum subsp. brasiliense } \\
\text { LMG21371T }\end{array}$ & 38.7 & 38.8 & 49.2 & 51.7 & 54.8 & 55.7 & 36.9 & 37.4 & 38.1 & 37.1 & 49.4 & - & 88.8 & 79.4 & 79.2 & 79.3 \\
\hline 13 & P. betavasculorum NCPPB2795T & 45.3 & 49.0 & 36.0 & 36.6 & 36.6 & 36.5 & 36.0 & 35.8 & 35.5 & 36.6 & 44.2 & 39.8 & - & 77.6 & 77.0 & 77.2 \\
\hline 14 & Dickeya dianthicola SS70 & 20.7 & 20.7 & 21.0 & 20.4 & 20.9 & 21.1 & 20.7 & 20.9 & 20.5 & 20.8 & 20 & 20.9 & 19.6 & - & 99.6 & 91.7 \\
\hline 15 & D. dianthicola NCPPB453T & 20.8 & 20.7 & 21.0 & 20.5 & 20.9 & 21.1 & 20.7 & 20.9 & 20.4 & 20.8 & 19.9 & 20.9 & 19.4 & 96.4 & - & 91.8 \\
\hline & D. solani IPO $2222 \mathrm{~T}$ & 21.2 & 21.2 & 20.8 & 21.0 & 21.1 & 21.6 & 21.2 & 21.5 & 20.8 & 21.5 & 19.8 & 21.6 & 19.6 & 46.3 & 46.4 & - \\
\hline
\end{tabular}

a Strains in bold are from this study. Dashes (-) differentiate the ANI and DDH value columns.

Table 4. Phenotypic characterization ${ }^{\mathrm{a}}$

\begin{tabular}{|c|c|c|c|c|c|c|c|c|c|c|}
\hline \multirow[b]{2}{*}{$\begin{array}{l}\text { Carbon source } \\
\text { (20\% conc.) }\end{array}$} & \multicolumn{10}{|c|}{ Bacterial strain } \\
\hline & $\begin{array}{l}\text { Pectobacterium } \\
\text { atrosepticum } \\
\text { SS26 }\end{array}$ & $\begin{array}{l}\text { P. polaris } \\
\text { SS28 }\end{array}$ & $\begin{array}{l}\text { P. parmentieri } \\
\text { SS90 }\end{array}$ & $\begin{array}{c}\text { P. punjabense } \\
\text { SS95 }\end{array}$ & $\begin{array}{c}\text { P. parmentieri } \\
\text { RNS 08-42-1A }\end{array}$ & $\begin{array}{l}\text { P. wasabiae } \\
\text { CFBP 3304 }\end{array}$ & $\begin{array}{l}\text { P. versatile } \\
\text { SS96 }\end{array}$ & $\begin{array}{l}\text { P. dianthicola } \\
\text { SS70 }\end{array}$ & $\begin{array}{c}\text { Dickeya } \\
\text { dianthicola } \\
\text { CFBP } 2015\end{array}$ & $\begin{array}{c}\text { D. solani } \\
0432.1\end{array}$ \\
\hline $\begin{array}{l}\text { 1-o-Methyl- } \beta \text {-D } \\
\text { glucopyranoside }\end{array}$ & + & + & + & + & + & + & + & NT & NT & NT \\
\hline $\begin{array}{l}\text { 1-o-Methyl- } \alpha \text {-D } \\
\text { glucopyranoside }\end{array}$ & - & - & - & - & - & - & - & NT & NT & NT \\
\hline D-lactose & + & + & + & + & + & - & + & NT & NT & NT \\
\hline Melibiose & + & + & + & + & + & - & + & + & + & + \\
\hline Glyconic acid & + & + & + & + & + & + & + & NT & NT & NT \\
\hline L-alanine & - & - & - & - & - & - & - & NT & NT & NT \\
\hline D-raffinose & + & + & + & + & + & - & + & + & + & + \\
\hline D-maltose & - & - & - & - & - & - & - & NT & NT & NT \\
\hline D-galactose & + & + & + & + & + & - & + & NT & NT & NT \\
\hline D-mannose & + & + & + & + & + & + & + & NT & NT & NT \\
\hline D-cellobiose & + & + & + & + & + & + & + & NT & NT & NT \\
\hline L-rhamnose & NT & NT & NT & NT & NT & NT & NT & + & + & - \\
\hline D-arabinose & NT & NT & NT & NT & NT & NT & NT & - & - & + \\
\hline
\end{tabular}

a $(+)$ indicates optical density $\left(\mathrm{OD}_{600}\right)>1.5 ;(-)$ indicates $\mathrm{OD}_{600}<0.04$; NT, not tested. 


\section{Literature Cited}

Adeolu, M., Alnajar, S., Naushad, S., and Gupta, R. S. 2016. Genome-based phylogeny and taxonomy of the 'Enterobacteriales': proposal for Enterobacterales ord. nov. divided into the families Enterobacteriaceae, Erwiniaceae fam. nov., Pectobacteriaceae fam. nov., Yersiniaceae fam. nov., Hafniaceae fam. nov., Morganellaceae fam. nov., and Budviciaceae fam. nov. Int. J. Syst. Evol. Microbiol. 66:5575-5599.

Alcorn, J. B., and Oldfield, M. L., eds. 1991. Biodiversity: Culture, Conservation, and Eco Development. Westview Press, Boulder, CO.

Ali, H. F., Ahmad, M., Junaid, M., Bibi, A., Ali, A., Sharif, M., Ali, B., and Sadozai, A. 2010. Blackleg and soft rot of potato in KPK: inoculum, sources, disease incidence and severity. Sarhad J. Agric. 26:397-404.

Brady, C. L., Cleenwerck, I., Denman, S., Venter, S. N., Rodríguez-Palenzuela, P., Coutinho, T. A., and De Vos, P. 2012. Proposal to reclassify Brenneria quercina (Hildebrand and Schroth 1967) Hauben et al. 1999 into a new genus, Lonsdalea gen. nov., as Lonsdalea quercina comb. nov., descriptions of Lonsdalea quercina subsp. quercina comb. nov., Lonsdalea quercina subsp. iberica subsp. nov. and Lonsdalea quercina subsp. britannica subsp. nov., emendation of the description of the genus Brenneria, reclassification of Dickeya dieffenbachiae as Dickeya dadantii subsp. dieffenbachiae comb. nov., and emendation of the description of Dickeya dadantii. Int. J. Syst. Evol. Microbiol. 62:1592-1602.

Caruso, A., Licciardello, G., La Rosa, R., Catara, V., and Bella, P. 2016. Mixed infection of Pectobacterium carotovorum subsp. carotovorum and P. carotovorum subsp. brasiliensis in tomato stem rot in Italy. J. Plant Pathol. 98:661-665.

Cigna, J., Dewaegeneire, P., Beury, A., Gobert, V., and Faure, D. 2017. A gapA PCR-sequencing assay for identifying the Dickeya and Pectobacterium potato pathogens. Plant Dis. 101:1278-1282.

Colston, S. M., Fullmer, M. S., Beka, L., Lamy, B., Gogarten, J. P., and Graf, J. 2014. Bioinformatics genome comparisons for taxonomic and phylogenetic assignments using Aeromonas as a test case. MBio 5:e2136-14.

Czajkowski, R., Perombelon, M. C., van Veen, J. A., and van der Wolf, J. M. 2011. Control of blackleg and tuber soft rot of potato caused by Pectobacterium and Dickeya species: a review. Plant Pathol. 60:999-1013.

Dees, M. W., Lysøe, E., Rossmann, S., Perminow, J., and Brurberg, M. B. 2017. Pectobacterium polaris sp. nov., isolated from potato (Solanum tuberosum). Int. J. Syst. Evol. Microbiol. 67:5222-5229.

Delcher, A. L., Phillippy, A., Carlton, J., and Salzberg, S. L. 2002. Fast algorithms for large-scale genome alignment and comparison. Nucleic Acids Res. 30:2478-2483.

Elbing, K., and Brent, R. 2002. Media preparation and bacteriological tools. Curr. Protoc. Mol. Biol. 59:1.1.1-1.1.7.

FAOSTAT. 2017. Food and Agricultural Organization Statistical database, Crop production. http://faostat3.fao.org/download/Q/QC/E

Faquihi, H., Terta, M., Amdan, M., Achbani, E. H., Ennaji, M. M., and Mhand, R. A. 2015. Phenotypic and genotypic diversity of Pectobacterium carotovorum subsp carotovorum causing soft rot disease of potatoes in Morocco. Eur. J. Plant Pathol. 143:801-811.

Farran, I., and Mingo-Castel, A. M. 2006. Potato minituber production using aeroponics: effect of plant density and harvesting intervals. Am. J. Potato Res. 83:47-53.

Gallelli, A., Galli, M., De Simone, D., Zaccardelli, M., and Loreti, S. 2009. Phenotypic and genetic variability of Pectobacterium carotovorum isolated from artichoke in the Sele valley. J. Plant Pathol.. 91:757-761.

Gardan, L., Gouy, C., Christen, R., and Samson, R. 2003. Elevation of three subspecies of Pectobacterium carotovorum to species level: Pectobacterium atrosepticum sp. nov., Pectobacterium betavasculorum sp. nov. and Pectobacterium wasabiae sp. nov. Int. J. Syst. Evol. Microbiol. 53: 381-391.

Glaeser, S. P., and Kämpfer, P. 2015. Multilocus sequence analysis (MLSA) in prokaryotic taxonomy. Syst. Appl. Microbiol. 38:237-245.

Hauben, L., Vauterin, L., Moore, E. R. B., Hoste, B., and Swings, J. 1999. Genomic diversity of the genus Stenotrophomonas. Int. J. Syst. Evol. Microbiol. 49:1749-1760.

Hélias, V., Hamon, P., Huchet, E., Wolf, J. V. D., and Andrivon, D. 2012. Two new effective semiselective crystal violet pectate media for isolation of Pectobacterium and Dickeya. Plant Pathol. 61:339-345.

Hoque, M. E., and Mansfield, J. W. 2005. A simple and reliable method for pathogenicity tests of bacterial blight disease of rice. Bangladesh J. Bot. 34:11-16.

Jiang, H. H., Hao, J. J., Johnson, S. B., Brueggeman, R. S., and Secor, G. 2016. First report of Dickeya dianthicola causing blackleg and bacterial soft rot on potato in Maine. Plant Dis. 100:2320.

Kado, C. I. 2010. Home Bacteriology Plant Bacteriology. Chapter 6: Macerative Diseases and Their Pathogens. APS Press, St. Paul, MN.

Khan, B. A., Haq, I., Iftikhar, S., and Aslam, M. 1985. Occurrence of late blight of potato in Pakistan. Pak. J. Bot. 17:163.

Khayi, S., Blin, P., Pédron, J., Chong, T. M., Chan, K. G., Moumni, M., Hélias, V., Van Gijsegem, F., and Faure, D. 2015. Population genomics reveals additive and replacing horizontal gene transfers in the emerging pathogen Dickeya solani. BMC Genomics 16:788.

Khayi, S., Cigna, J., Chong, T. M., Quêtu-Laurent, A., Chan, K. G., Hélias, V., and Faure, D. 2016. Transfer of the potato plant isolates of Pectobacterium wasabiae to Pectobacterium parmentieri sp. nov. Int. J. Syst. Evol. Microbiol. 66:5379-5383.

Ma, B., Hibbing, M. E., Kim, H. S., Reedy, R. M., Yedidia, I., Breuer, J., Breuer, J., Glasner, J. D., Perna, N. T., Kelman, A., and Charkowski, A. O. 2007. Host range and molecular phylogenies of the soft rot enterobacterial genera Pectobacterium and Dickeya. Phytopathol. 97:1150-1163.

Mansfield, J., Genin, S., Magori, S., Citovsky, V., Sriariyanum, M., Ronald, P., Dow, M. A. X., Verdier, V., Beer, S. V., Machado, M. A., and Toth, I. A. N. 2012. Top 10 plant pathogenic bacteria in molecular plant pathology. Mol. Plant Pathol. 13:614-629.

McNally, R. R., Curland, R. D., Webster, B. T., Robinson, A. P., and Ishimaru, C. A. 2017. First report of Pectobacterium carotovorum subsp. brasiliensis causing blackleg and stem rot in commercial and seed potato fields in Minnesota and North Dakota. Plant Dis. 101:1672.

Meier-Kolthoff, J. P., Auch, A. F., Klenk, H. P., and Göker, M. 2013. Genome sequence-based species delimitation with confidence intervals and improved distance functions. BMC Bioinformatics 14:60.

Nabhan, S., De Boer, S. H., Maiss, E., and Wydra, K. 2013. Pectobacterium aroidearum sp. nov., a soft rot pathogen with preference for monocotyledonous plants. Int. J. Syst. Evol. Microbiol. 63:2520-2525.

Nabhan, S., Wydra, K., Linde, M., and Debener, T. 2012. The use of two complementary DNA assays, AFLP and MLSA, for epidemic and phylogenetic studies of pectolytic enterobacterial strains with focus on the heterogeneous species Pectobacterium carotovorum. Plant Pathol. 61: 498-508.

Nykyri, J., Niemi, O., Koskinen, P., Nokso-Koivisto, J., Pasanen, M., Broberg, M., Plyusnin, I., Törönen, P., Holm, L., Pirhonen, M., and Palva, E. T. 2012. Revised phylogeny and novel horizontally acquired virulence determinants of the model soft rot phytopathogen Pectobacterium wasabiae SCC3193. PLoS Pathog 8: e1003013.

Oulghazi, S., Cigna, J., Lau, Y. Y., Moumni, M., Chan, K. G., and Faure, D. 2019a. Transfer of the waterfall source isolate Pectobacterium carotovorum M022 to Pectobacterium fontis sp. nov., a deep-branching species within the genus Pectobacterium. Int. J. Syst. Evol. Microbiol. 69:470-475.

Oulghazi, S., Pédron, J., Cigna, J., Lau, Y. Y., Moumni, M., Van Gijsegem, F., Chan, K. G., and Faure, D. 2019b. Dickeya undicola sp. nov., a novel species for pectinolytic isolates from surface waters in Europe and Asia. Int J. Syst. Evol. Microbiol. 69:2440-2444.

Ozturk, M., Aksoy, H. M., Potrykus, M., and Lojkowska, E. 2018. Genotypic and phenotypic variability of Pectobacterium strains causing blackleg and soft rot on potato in Turkey. Eur. J. Plant Pathol. 152:143-155.

Patel, N., Baldwin, A. C., Patel, R. D., Kobayashi, D. Y., and Wyenandt, C. A. 2019. First report of Dickeya dianthicola causing blackleg and soft rot on potato (Solanum tuberosum) in New Jersey, USA. Plant Dis. 103:146.

Pédron, J., Bertrand, C., Taghouti, G., Portier, P., and Barny, M. A. 2019 Pectobacterium aquaticum sp. nov., isolated from waterways. Int. J. Syst. Evol. Microbiol. 69:745-751.

Portier, P., Pédron, J., Taghouti, G., Fischer-Le Saux, M., Caullireau, E., Bertrand, C., Laurent, A., Chawki, K., Oulgazi, S., Moumni, M. and Andrivon, D. 2019. Elevation of Pectobacterium carotovorum subsp. odoriferum to species level as Pectobacterium odoriferum sp. nov., proposal of Pectobacterium brasiliense sp. nov. and Pectobacterium actinidiae sp. nov., emended description of Pectobacterium carotovorum and description of Pectobacterium versatile $\mathrm{sp}$. nov., isolated from streams and symptoms on diverse plants. Int. J. Syst. Evolution. Microbiol. p.ijsem003611.

Potrykus, M., Golanowska, M., Sledz, W., Zoledowska, S., Motyka, A., Kolodziejska, A., and Lojkowska, E. 2016. Biodiversity of Dickeya spp. isolated from potato plants and water sources in temperate climate. Plant Dis. 100:408-417.

Pritchard, L., Glover, R. H., Humphris, S., Elphinstone, J. G., and Toth, I. K. 2016. Genomics and taxonomy in diagnostics for food security: soft-rotting enterobacterial plant pathogens. Anal. Methods 8:12-24.

Rosselló-Mora, R., and Amann, R. 2001. The species concept for prokaryotes. FEMS Microbiol. Rev. 25:39-67.

Rosenzweig, N., Steere, L., Kirk, W. W., Mambetova, S., Long, C., Schafer, R., Dangi, S., and Byrne, J. 2016. First report of Dickeya dianthicola and Pectobacterium wasabiae causing aerial stem rot of potato in Michigan, USA. New Dis. Rep. 33:10.

Sambrook, J., and Russell, D. W. 2001. Cloning: A Laboratory Manual. Vol. 2, 3rd Ed. Cold Spring Harbor Laboratory Press, New York, NY.

Samson, R., Legendre, J. B., Christen, R., Fischer-Le Saux, M., Achouak, W., and Gardan, L. 2005. Transfer of Pectobacterium chrysanthemi (Burkholder et al. 1953) Brenner et al. 1973 and Brenneria paradisiaca to the genus Dickeya gen. nov. as Dickeya chrysanthemi comb. nov. and Dickeya paradisiaca comb. nov. and delineation of four novel species, Dickeya dadantii sp. nov., Dickeya dianthicola sp. nov., Dickeya dieffenbachiae sp. nov. and Dickeya zeae sp. nov. Int. J. Syst. Evol. Microbiol. 55:1415-1427.

Sarfraz, S., Riaz, K., Oulghazi, S., Cigna, J., Sahi, S. T., Khan, S. H., and Faure, D. 2018. Pectobacterium punjabense sp. nov., isolated from blackleg symptoms of potato plants in Pakistan. Int. J. Syst. Evol. Microbiol. 68:3551-3556.

Schaad, N. W., Jones, J. B., and Chun, W. 2001. Laboratory Guide for the Identification of Plant Pathogenic Bacteria, 3rd ed. APS Press, St. Paul, MN.

Terta, M., El Karkouri, A., M'hand, R. A., Achbani, E., Barakate, M., Amdan, M., Annajar, B., El Hassouni, M., Val, F., Bouteau, F., and Ennaji, M. M. 2010. 
Occurrence of Pectobacterium carotovorum strains isolated from potato soft rot in Morocco. Cell. Mol. Biol. 56:1324-1333.

Toth, I. K., Van Der Wolf, J. M., Saddler, G., Lojkowska, E., Hélias, V., Pirhonen, M., Tsror, L., and Elphinstone, J. G. 2011. Dickeya species: an emerging problem for potato production in Europe. Plant Pathol. 60:385-399.

van der Wolf, J. M., Nijhuis, E. H., Kowalewska, M. J., Saddler, G. S., Parkinson, N., Elphinstone, J. G., Pritchard, L., Toth, I. K., Lojkowska, E., Potrykus, M., and Waleron, M. 2014. Dickeya solani sp. nov., a pectinolytic plant-pathogenic bacterium isolated from potato (Solanum tuberosum). Int. J. Syst. Evol. Microbiol. 64:768-774.

Waleron, M., Misztak, A., Waleron, M., Franczuk, M., Jońca, J., Wielgomas, B., Mikiciński, A., Popović, T., and Waleron, K. 2019a. Pectobacterium zantedeschiae sp. nov. a new species of a soft rot pathogen isolated from Calla lily (Zantedeschia spp.). Syst. Appl. Microbiol. 42:275-283.

Waleron, M., Misztak, A., Waleron, M., Franczuk, M., Wielgomas, B., and Waleron, K. 2017. Transfer of Pectobacterium carotovorum subsp. carotovorum strains isolated from potatoes grown at high altitudes to Pectobacterium peruviense $\mathrm{sp}$. nov. Syst. Appl. Microbiol. 41:85-93.

Waleron, M., Misztak, A., Waleron, M., Jonca, J., Furmaniak, M., Waleron, K. 2019b. Pectobacterium polonicum sp. nov. isolated from vegetable fields. Int. J. Syst. Evolution. Microbiol. 69:1751-1759.

Wright, D., Bwye, A., Banovic, M., Baulch, J., Wang, C., Hair, S., Hammond, N., Coutts, B., and Kehoe, M. 2018. First report of Dickeya dianthicola in potatoes in Australia. Plant Dis. 102:2029.

Yahiaoui-Zaidi, R., Jouan, B., and Andrivon, D. 2003. Biochemical and molecular diversity among Erwinia isolates from potato in Algeria. Plant Pathol. 52:28-40.

Zhang, Y., Fan, Q., and Loria, R. 2016. A re-evaluation of the taxonomy of phytopathogenic genera Dickeya and Pectobacterium using whole-genome sequencing data. Syst. Appl. Microbiol. 39:252-259.

Zhang, Y., and Qiu, S. 2015. Examining phylogenetic relationships of Erwinia and Pantoea species using whole genome sequence data. Antonie van Leeuwenhoek 108:1037-1046. 